\title{
Erratum to: Ceramic ChemCam Calibration Targets on Mars Science Laboratory
}

\author{
D. Vaniman • M.D. Dyar $\cdot$ R. Wiens $\cdot$ A. Ollila $\cdot$ \\ N. Lanza $\cdot$ J. Lasue $\cdot$ J.M. Rhodes $\cdot$ S. Clegg $\cdot$ \\ H. Newsom
}

Published online: 14 August 2012

(C) Springer Science+Business Media B.V. 2012

\section{Erratum to: Space Sci. Rev. \\ DOI 10.1007/s11214-012-9886-0}

In Fig. 4 of this article, panel b is mislabeled by repetition of the label for panel a, "NAu-2 low $\mathrm{S}$ ". A corrected figure is shown here, where panel b is labelled "NAu-2 mid S".

The online version of the original article can be found under doi:10.1007/s11214-012-9886-0.

D. Vaniman $(\bowtie)$

Planetary Science Institute, Tucson, AZ 85719, USA

e-mail:dvaniman@psi.edu

M.D. Dyar

Dept. of Astronomy, Mount Holyoke College, South Hadley, MA 01075, USA

R. Wiens · N. Lanza

Space Remote Sensing, Los Alamos National Laboratory, Los Alamos, NM 87545, USA

A. Ollila $\cdot$ H. Newsom

Institute of Meteoritics, University of New Mexico, Albuquerque, NM 87131, USA

J. Lasue

Observatoire Midi-Pyrénées, Institut de Recherche en Astrophysique et Planétologie, Toulouse, France

J.M. Rhodes

Dept. of Geosciences, University of Massachusetts, Amherst, MA 01003, USA

S. Clegg

Physical Chemistry and Applied Spectroscopy, Los Alamos National Laboratory, Los Alamos, NM 87545, USA 

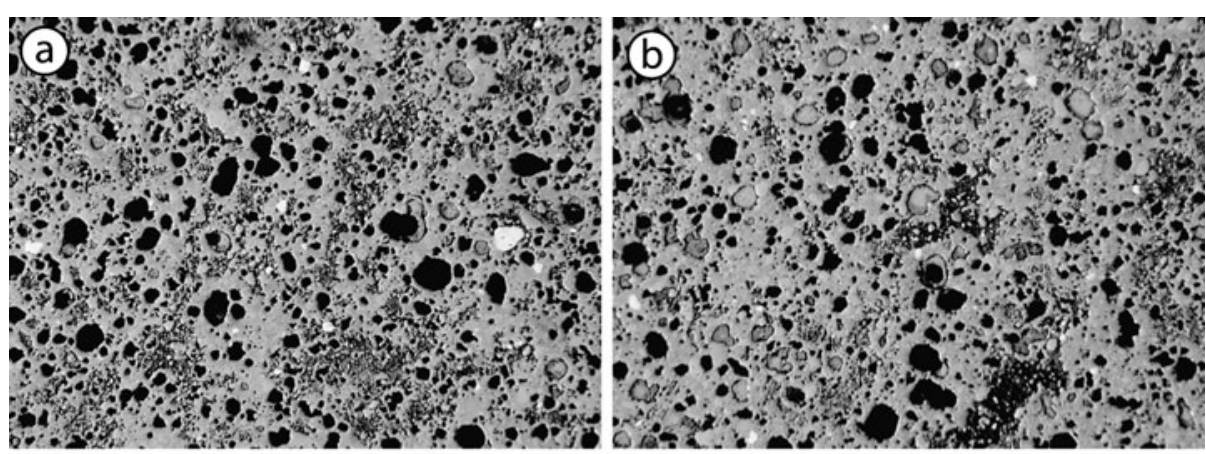

\section{NAu-2 low $S$}

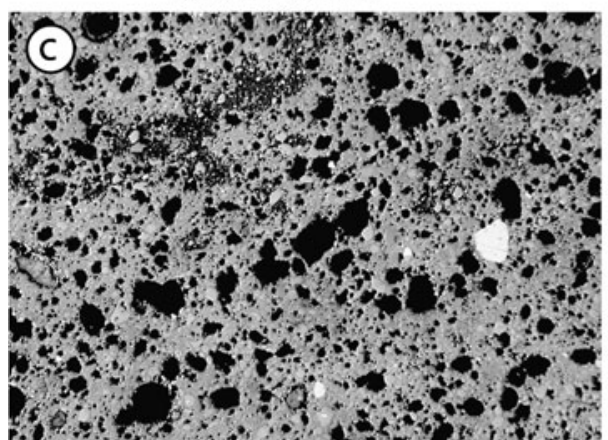

NAu-2 mid S

\section{NAu-2 high S $\quad \underline{200 \mu m} \quad$ KGa-2 mid S}

Fig. 4 Reflected-light photomicrographs of $30 \mu \mathrm{m}$ thick doubly-polished thin sections of ChemCam ceramic targets. Dark spots are epoxy-filled vesicles; bright grains in the NAu-2 samples are hematite 